\title{
Utilizing Risk Scores in Determining the Optimal Revascularization Strategy for Complex Coronary Artery Disease
}

\author{
Vasim Farooq • Salvatore Brugaletta • \\ Patrick W. Serruys
}

Published online: 6 August 2011

(C) The Author(s) 2011. This article is published with open access at Springerlink.com

\begin{abstract}
Percutaneous coronary intervention (PCI) of multivessel and/or left main stem disease have been shown to be potentially legitimate revascularization alternatives in appropriately selected patients. Risk stratification is an important component in guiding patients to identify the most appropriate revascularization modality (PCI or coronary artery bypass grafting $[\mathrm{CABG}]$ ) in conjunction with the Heart Team. The aim of this paper is to give the clinician a concise overview of the important established and evolving contemporary risk models in aiding this decision-making process. Risk models, based on clinical and anatomical variables alone, the novel concept of functional anatomical risk scores, and risk models combining aspects from both clinical and anatomical scores, are all discussed. The emerging concepts of the patientempowered risk/benefit tradeoff between PCI and CABG to help personalize the choice of revascularization modality are also explored.
\end{abstract}

Keywords Risk scores - Complex coronary artery disease . SYNTAX score - Clinical SYNTAX score · Functional SYNTAX score · EuroSCORE - NERS · ACEF - Mayo clinic risk score $\cdot$ Global risk $\cdot$ Revascularization strategy

\section{Clinical Trial Acronyms}

ARTS Arterial Revascularization Therapies Study

FAME Fractional Flow Reserve Versus Angiography for Guiding PCI in Patients with Multivessel Evaluation

V. Farooq $\cdot$ S. Brugaletta $\cdot$ P. W. Serruys $(\bowtie)$

Department of Interventional Cardiology,

Erasmus University Medical Centre, Thoraxcenter,

's-Gravendijkwal 230,

3015 CE Rotterdam, the Netherlands

e-mail: p.w.j.c.serruys@erasmusmc.nl
LEADERS Limus Eluted from a Durable Versus

Erodable Stent Coating

RESEARCH Rapamycin-Eluting Stent Evaluated at Rotterdam Cardiology Hospital

SYNTAX Synergy Between Percutaneous Coronary Intervention with TAXUS and Cardiac Surgery

T-SEARCH Taxus Stent Evaluated at Rotterdam Cardiology Hospital.

\section{Introduction}

Risk stratification is an integral and increasingly important aspect of the assessment of patients with complex coronary artery disease who are candidates for coronary revascularization. Although the landmark SYNTAX trial established that surgery was the standard of care for patients with left main stem (LMS) and/or multivessel disease, an important finding from this study was that patients with less complex disease were found to have equivalent outcomes to surgery at 1 and 3 years' follow-up [1, 2•, 3].

The "Heart Team" approach in managing these complex patients was pioneered within the SYNTAX trial, and has recently been incorporated as a class I recommendation in recent myocardial revascularization guidelines [4]. As part of this approach, risk models to appropriately stratify patients are crucial to aid in the decision-making process regarding the choice of revascularization modality. Within cardiothoracic practice, the use of risk scores are well established and are predominantly related to clinical variables alone, with the EuroSCORE (European System for Cardiac Operative Risk Evaluation) being in widespread contemporary use $[5,6]$. 
With percutaneous coronary intervention (PCI) of complex coronary artery disease, the risk models are still evolving, with models consisting of clinical or anatomical variables alone or combinations of the two variable types. Whereas anatomical variables have been shown to be less important for surgical outcomes, the SYNTAX trial and subsequent studies have confirmed these to be of significant importance for multivessel PCI $[7,8]$. However, there is recognition that both anatomical and clinical variables are required to appropriately risk stratify patients contemplating percutaneous revascularization.

The purpose of this review article is to explore the numerous types of risk scores that are available that take into account either anatomical or clinical variables alone or a combination (Table 1). We also aim to highlight areas of potential further developments of contemporary risk models - in particular, the emerging concept of a risk/ benefit tradeoff-all of which may ultimately allow the individual patient and the Heart Team to best determine the most appropriate revascularization strategy.

\section{Anatomical- and Functional-Based Risk Scores}

In 1981, our group developed a coronary scoring system that assessed the severity and extent of the underlying coronary artery disease [8]. This system was based on the severity of luminal diameter narrowing and weighted according to the usual flow to the left ventricle in each coronary vessel. Consequently the most weight was given to the LMS, followed by the left anterior descending, circumflex, and right coronary arteries. This early pioneering work ultimately formed the basis of the SYNTAX score (SXscore) [7, 9]. Since then, numerous angiographic-based risk scores have been developed (Table 1), several of which are described below.

\section{American College of Cardiology/American Heart \\ Association Lesion Classification System}

The American College of Cardiology/American Heart Association (ACC/AHA) lesion classification system was one of the first angiographic scoring systems developed, comprising of 11 angiographic variables with all lesions categorized into types (A, B1, B2, and C) [10]. This system was predictive of the angiographic success of PCI with a subsequent prognostic effect on the early and late clinical outcomes in the pre drug-eluting stent era. However, registry data from the drug-eluting stent era have had conflicting results. The German Cypher registry $(n=6755)$ failed to show any significant association with clinical outcomes at 6 months [11]; conversely, data from the ARTS II registry suggested an association with clinical outcomes for two and three-vessel disease (3VD) [12]. Furthermore, a small registry $(n=255)$ demonstrated this classification system to be potentially predictive of mortality in unprotected LMS PCI at 1-year follow-up [13].

\section{SYNTAX Score}

The SXscore is a well-described anatomical risk-based score that takes into account features such as bifurcations, total occlusions, thrombus, calcification, small vessels, and so forth. Each coronary lesion with a greater than $50 \%$ luminal obstruction lumen in vessels $\geq 1.5 \mathrm{~mm}$ are separately scored and summated to provide the overall SXscore. This is calculated using dedicated software that integrates the number of lesions with their specific weighting factors, based on the amount of myocardium distal to the lesion and morphologic features of each single lesion [7, 8, 9, 14].

Within the SYNTAX trial, [1] the distribution of the SXscore was found to be Gaussian in the randomized PCI and coronary artery bypass grafting $(\mathrm{CABG})$ populations with the curves almost being superimposable (Fig. 1). When the scores of the randomized SYNTAX population were divided into tertiles, the upper boundary of the lowest tertile was 22 (low risk), the second tertile ranged from 23 to 32 (intermediate risk), and the lower boundary for the highest tertile is $\geq 33$ (high risk).

The SXscore has since been consistently shown to demonstrate poorer outcomes and to be an independent predictor of major adverse cardiac events (MACE) in the high tertile group of risk for PCI with both multivessel and LMS disease at up to 5 years of follow-up [15]. This is maintained even with next-generation drug-eluting stents. For example, Wykrzykowska et al. [16] demonstrated in the LEADERS all-comers trial a higher rate of myocardial infarction (MI), target vessel revascularization, and MACE in highest tertile of the SXscore Of note is that within this study approximately $30 \%$ of the high SXscore risk tertile had 3VD compared with only $10 \%$ in the low SXscore risk tertile.

Within the CABG population, the SXscore however appears to have little predictive value for outcome. This is likely due to the simple fact that the bypass is anastomosed distal to the severe coronary disease, regardless of the complexity, provided there are suitable graftable targets [17].

\section{Functional SYNTAX Score}

The FAME study first established that by utilizing fractional flow reserve (FFR) measurements to determine the functional significance of individual coronary lesions and guide subsequent coronary intervention, that this leads to a potential prognostic impact when compared with angiographic guidance alone [18-20]. Consequently, by incorporating FFR measurements into the SXscore to form the 
Table 1 Summary of a selection of established and contemporary risk models categorized by anatomical, clinical, or combined types for the assessment of risk in patients proposing to undergo revascularization

\begin{tabular}{|c|c|c|c|}
\hline \multirow[t]{2}{*}{ Clinical risk score } & \multicolumn{2}{|c|}{$\begin{array}{l}\text { Number of variables used } \\
\text { to calculate risk }\end{array}$} & \multirow[t]{2}{*}{ Outcomes } \\
\hline & Clinical & Angiographic & \\
\hline \multicolumn{4}{|c|}{ Anatomical- and functional-based scores } \\
\hline $\begin{array}{l}\text { ACC/AHA lesion } \\
\text { classification }\end{array}$ & 0 & 11 (per lesion) & $\begin{array}{l}\text { Pre drug-eluting stent era: predictive of angiographic success of PCI and prognostic effect on early and late } \\
\text { clinical outcomes. Conflicting results in the drug-eluting stent era [10-13] }\end{array}$ \\
\hline $\begin{array}{l}\text { Myocardial Jeopardy } \\
\text { scores }\end{array}$ & & & $\begin{array}{l}\text { Encompasses severity of coronary artery lesions and the volume of myocardium subtended by the } \\
\text { stenosis (ie, amount of myocardium at risk) }\end{array}$ \\
\hline -Duke Jeopardy score & 0 & $6^{\mathrm{a}}$ & \\
\hline $\begin{array}{l}\text {-Myocardial Jeopardy } \\
\text { index (BARI) }\end{array}$ & 0 & 9 & All predictive of mortality at 1 year after PCI or CABG [51]. \\
\hline $\begin{array}{l}\text {-APPROACH lesion } \\
\text { score }\end{array}$ & 0 & $10^{\mathrm{a}}$ & $\begin{array}{l}\text { PCI: APPROACH lesion score most predictive } \\
\text { CABG: Duke Jeopardy score most predictive }\end{array}$ \\
\hline $\begin{array}{l}\text { SYNTAX score } \\
\text { (SXscore) }\end{array}$ & 0 & 11 (per lesion) & $\begin{array}{l}\text { Quantifies coronary artery disease complexity by tertiles of SXscore: more events (death, MACCE) in } \\
\text { the higher tertiles of risk at up to } 3 \text { years follow-up }[2 \cdot 7]\end{array}$ \\
\hline $\begin{array}{l}\text { Functional SYNTAX } \\
\text { score }\end{array}$ & 0 & 11 (per lesion) & $\begin{array}{l}\text { FFR-guided SXscore calculation improved prognostic ability of the SXscore: death/MI, MACE at } \\
1 \text { year [21] }\end{array}$ \\
\hline \multicolumn{4}{|l|}{ Clinical-based scores } \\
\hline Parsonnet score & 14 & 0 & Operative mortality after open heart surgery [36] \\
\hline $\begin{array}{l}\text { New Mayo Clinic risk } \\
\text { score }\end{array}$ & 7 & 0 & $\begin{array}{l}\text { Procedural death and MACE for PCI [24] } \\
\text { In-hospital death with CABG or PCI [25] }\end{array}$ \\
\hline $\begin{array}{l}\text { EuroSCORE (additive } \\
\text { or logistic) }\end{array}$ & 17 & 0 & $\begin{array}{l}\text { Operative mortality for all forms of cardiothoracic surgery }[5,6] \\
\text { Evidence for predicting death or MACCE in high-risk tertiles for PCI [27-29•, 30-32] }\end{array}$ \\
\hline $\begin{array}{l}\text { NCDR CathPCI risk } \\
\text { score }\end{array}$ & 8 & 0 & 30-day mortality rates after PCI in all patient types [52•] \\
\hline ACEF score (age, & 3 & 0 & Operative mortality in elective cardiac operations $[33,34 \cdot]$ \\
\hline $\begin{array}{l}\text { creatinine, ejection } \\
\text { fraction) }\end{array}$ & & & $\begin{array}{l}\text { Predictor of cardiac death and MI at } 1 \text { year after PCI; inferior to the SXscore at predicting overall } \\
\text { MACE and the risk of repeat revascularization [35] }\end{array}$ \\
\hline $\begin{array}{l}\text { Northern New } \\
\text { England score }\end{array}$ & 8 & 0 & In-hospital mortality after CABG [53] \\
\hline $\begin{array}{l}\text { New York CABG risk } \\
\text { index }\end{array}$ & 10 & 0 & In-hospital mortality after CABG [54] \\
\hline \multicolumn{4}{|c|}{ Combined (anatomical and clinical based) risk scores } \\
\hline $\begin{array}{l}\text { Society of Thoracic } \\
\text { Surgery score }\end{array}$ & 40 & 2 & Operative morbidity and mortality for all forms of cardiothoracic surgery [55-57] \\
\hline $\begin{array}{l}\text { The Texas Heart } \\
\text { Institute risk score }\end{array}$ & 8 & $\begin{array}{l}\text { Angiographic: } \\
2 \\
\text { Procedural: } 1^{\mathrm{b}}\end{array}$ & Predictors of in-hospital MACE after PCI or CABG [58] \\
\hline $\begin{array}{l}\text { New York PCI risk } \\
\text { score }\end{array}$ & 8 & 1 & In-hospital death for PCI procedures [59] \\
\hline $\begin{array}{l}\text { Parsonnet+SYNTAX } \\
\text { score }\end{array}$ & 14 & 11 & MACCE and death at a median follow-up of 973 days (PCI) and 1298 days (CABG) [38] \\
\hline $\begin{array}{l}\text { Clinical SYNTAX } \\
\text { score }\end{array}$ & 3 & 11 (per lesion) & MACCE and death after PCI at 5 years follow-up [41] \\
\hline NERS & 17 & $\begin{array}{l}\text { Angiographic: } \\
33 \\
\text { Procedural: } 4^{\mathrm{c}}\end{array}$ & 6-month cardiac death and cumulative MACE after unprotected LMS PCI [44] \\
\hline Global Risk & 17 & 11 (per lesion) & Death and MACCE after unprotected LMS PCI $[43,46]$ \\
\hline
\end{tabular}

${ }^{\text {a }}$ Number of segments of myocardium at risk

${ }^{\mathrm{b}}$ Number of stents.

${ }^{\mathrm{c}}$ Need of IABP, two-stent technique, IVUS guidance

$A C C$ American college of cardiology, AHA American heart association, APPROACH Alberta provincial project for outcome assessment in coronary heart disease, BARI bypass angioplasty revascularization investigation, $C A B G$ coronary artery bypass grafting, EuroSCORE European system for cardiac operative risk evaluation, IABP intra-aortic balloon pump, IVUS intravascular ultrasound, LMS left main stem, MACE major adverse cardiac events, $M A C C E$ major adverse cardiac and cerebrovascular events, $M I$ myocardial infarction, $N C D R$ national cardiovascular data registry, NERS new risk classification score, PCI percutaneous coronary intervention, SYNTAX synergy between percutaneous coronary intervention with taxus and cardiac surgery 


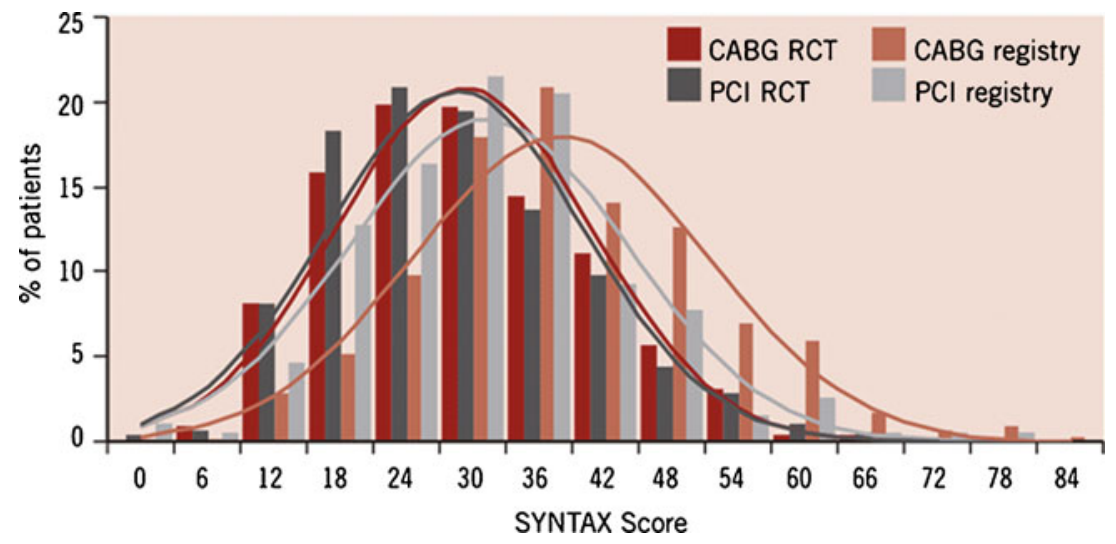

Fig. 1 The distribution of the SYNTAX score in the randomized and registry PCI and CABG populations from the SYNTAX trial. Note how the distributions for both the PCI and CABG registries are shifted to the right, whereas for the randomized population both curves are almost superimposable on each other $[1,7]$. $C A B G$ coronary artery bypass grafting, $P C I$ percutaneous coronary intervention, $R C T$ randomized

recently dubbed, Functional SYNTAX score, it was shown in a retrospective subanalysis of almost 500 patients with multivessel disease from the FFR-guided arm of FAME, that this improved the risk stratification of patients when compared with the conventional angiographic-based SXscore [21]. The primary benefit appeared in reclassifying a significant proportion of the higher-risk groups into lower-risk categories while still maintaining a significantly higher event rate (death/MI and MACE at 1 year) in the high-risk groups. However, the study did not include LMS disease, and from a practical perspective, even if validated in larger prospective populations, is limited by the more invasive nature of the procedure.

One of the criticisms of the FAME study was that quantitative coronary angiography (QCA) was not used to assess vessel size and instead was reliant on visual estimation [22]. Visual assessment is well known to be associated with poor reproducibility and often overestimates lesion significance [10]. If QCA had been used to assess vessel size, then the potential benefit seen in favor of FFR may have been less. The practice of visual assessment of vessel/lesion size is however representative of real-life practice and was also the basis of how the SXscores were calculated within the SYNTAX study. Novel techniques to potentially simplify the generation of the newly developed Functional SYNTAX score include the use of noninvasive computed tomographic angiography that allows for the simultaneous assessment of anatomy and the measurement of the hemodynamic significance of lesions (Heartflow, Redwood City, California, USA) .

\section{Limitations}

The progressive development of anatomical-based risk scores culminating in the Functional SYNTAX score has controlled trial, SYNTAX Synergy Between Percutaneous Coronary Intervention with TAXUS and Cardiac Surgery. (Reprinted from EuroIntervention; Serruys PW, Onuma Y, Garg S, et al.: Assessment of the SYNTAX score in the Syntax study. Copyright 2009, with permission from Europa Edition); [7]

undoubtedly improved the performance of these risk models in terms of stratification for the individual patient. However, the limiting factors are the inevitable variability in coronary angiogram assessment if visual assessment is used to assess the vessel/lesion size [7, 23]. With the potential use of the Functional SYNTAX score this problem may be circumvented, especially if a noninvasive assessment of the Functional SYNTAX score is developed as mentioned. The other limiting factors are that no clinical variables are used, which in themselves are less subjective than some angiographic variables; consequently, important prognostic information may potentially be missing that may aid in risk stratifying these patients further.

\section{Clinical-Based Risk Scores}

The main advantages of clinical-based scores are that they are potentially easier to perform and less subjective compared with purely anatomical-based scores that require interpretation of the coronary angiogram. They can also be performed relatively quickly and often at bedside if necessary.

\section{EuroSCORE}

The EuroSCORE is an established risk model, which utilizes 17 clinical variables within cardiothoracic practice for predicting operative mortality $[5,6,26]$. In use since 1999 , the model was derived from almost 20,000 consecutive patients from 128 hospitals in eight European countries. The additive model assigns an individual score to 17 clinical variables and has been validated in many populations around the world. These studies have consistently demonstrated that among 
cardiothoracic surgery patients, a low EuroSCORE risk tertile ranges from 1 to 2 , intermediate-risk tertile from 3 to 5 , and a high-risk tertile of $6+$ (Table 2 ). The subsequently developed logistic EuroSCORE allows for a more accurate risk prediction within the CABG cohort, in particular for the high-risk patient in which the additive model was found to lead to a potential underestimation of risk.

Kim et al. [27] first demonstrated that the high-risk tertile of the EuroSCORE was an independent predictor of death/MI after unprotected LMS intervention with sirolimus-eluting stents. Subsequently, Romagnoli et al. [28] applied the additive EuroSCORE to predict in-hospital mortality in 1173 consecutive patients undergoing PCI in a single high-volume center and correlated the higher-risk tertiles of the EuroSCORE with in-hospital mortality. This included patients who had undergone unprotected LMS PCI [28]. In addition, several studies have since all identified the additive EuroSCORE as an independent predictor of major adverse cardiac and cerebrovascular events (MACCE) among patients with unprotected LMS PCI at up to 4 years of follow-up [27, 29•, 30-32]. Only one study has examined the logistic EuroSCORE in PCI patients; however, little differences were found in stratifying risk when compared with the additive EuroSCORE [28].

\section{ACEF Score}

Ranucci et al. [33, 34•] demonstrated in a relatively simple risk model consisting of only three clinical variables - age, preoperative serum creatinine value, and left ventricular ejection fraction - a risk model for assessing operative mortality risk in elective cardiac operations. Of note is that despite the simplicity of the model, its clinical performance appeared to be equivalent to either the additive or the logistic EuroSCOREs [33, 34•].

The ACEF score is calculated using the formula:

$\mathrm{ACEF}=[$ Age $/$ Ejection fraction $(\%)]+[1($ if creatinine $>2 \mathrm{mg} / \mathrm{dL})]$.

From this score, a mortality risk can be calculated from a graphical relationship of the score with an operative risk or an equation $[33,34 \cdot]$.

The ACEF model was recently applied to PCI patients from the all-comers LEADERS population at 1-year follow-up [35]. Despite the ACEF score being demonstrated to be superior to the SXscore alone as a predictor of cardiac death and MI after PCI, the ACEF score was found to be inferior to the SXscore at predicting overall MACE and the risk of repeat revascularization. This reflects the observation that anatomical and clinical variables appear to be a necessary requirement for a comprehensive risk model in predicting clinical outcomes with PCI.

\section{Limitations}

The main limitations of the clinical-based risk scores alone are predominantly related to the lack of anatomical variables which in themselves may carry additional prognostic information, such as the SYNTAX score as previously discussed.

\section{Combined (Anatomical and Clinical) Based Risk Scores}

SYNTAX Score and the Parsonnet Score

By combining the Parsonnet score, an operative risk score published in 1989 consisting of 14 clinical variables [36], with the SXscore, it has been shown that this may potentially improve the performance of the SXscore alone. In 2005, Valgimigli et al. [37] demonstated that the Parsonnet score was an independent predictor of MACE after LMS intervention from the Rotterdam RESEARCH and T-SEARCH registries. More recently, Chakravarty et al. [38] demonstrated that by adding the Parsonnet score as a covariate to the SXscore, this improved the ability of the score in predicting MACCE after LMS PCI.

\section{Clinical SYNTAX Score}

The underlying rationale for the Clinical SYNTAX Score was to combine, by multiplication, the SXscore and a variant of the ACEF score (modified ACEF score), of which the latter had proven to be comparable to the EuroSCORE in elective CABG patients as previously described [33, 34•]. The modified ACEF score was used instead of ACEF score in this model as it had previously been demonstrated that this potentially allowed for a more accurate assessment of the underlying renal function and had subsequently improved the accuracy of cardiac prediction models such as the EuroSCORE [39-41]. The modified ACEF score is calculated by using the formula: age/ejection fraction +1 point for every $10-\mathrm{ml} / \mathrm{min}$ reduction in creatinine clearance below $60 \mathrm{ml} / \mathrm{min} / 1.73 \mathrm{~m}^{2}$ (up to a maximum of 6 points).

This model was applied to the ARTS II population treated with sirolimus-eluting stents for multivessel coronary artery disease by our group [41, 42]. By dividing the calculated Clinical SYNTAX scores into tertiles of risk, it was demonstrated that the risk model for predicting outcomes for MACCE and death at 5 years was superior to the SXscore or modified ACEF scores alone. One of the limiting factors of the Clinical SYNTAX score was that despite being able to predict events accurately in the highrisk tertile, the risk model was unable to discriminate between the end points for the low- and intermediate-risk 
tertiles [41]. This was also recently demonstrated within a registry of patients undergoing left main PCI [43].

\section{New Risk Classification Score}

The New Risk Classification Score (NERS) [44] is a risk model developed to predict outcomes for unprotected LMS PCI from four centers in China $(n=260)$. Reflecting the long period over which this registry was performed ( $\sim 10$ years), the patients included had either bare-metal or drug-eluting stent implantation. The model was subsequently validated in a different consecutive group of patients within the same registry all treated with drug-eluting stents $(n=337)$.

This risk model consists of 54 variables (17 clinical, 4 procedural, and 33 angiographic features). A substantially higher c-statistic was evident for the NERS compared with the SXscore (NERS: 0.89 vs SXscore: 0.69), indicating that it had an excellent discriminatory ability. When the NERS score was separated into two groups of risk (high and low) and clinical outcomes assessed, the high-risk group was demonstrated to be significantly more predictive of MACE compared with the intermediate or high SXscore tertiles.

In the low-risk NERS group, outcomes were similar to the low SXscore group, suggesting at least from this study that anatomical variables alone may be sufficient to be predict outcomes in the low-risk group. However, patient comorbidity was significantly less prevalent in the NERS patient population compared with the all-comers SYNTAX population [1, 3], the latter of which was designed to overcome many of the limitations/bias selections inherent in small registries. Validation of the NERS risk model in a much larger, randomized population of patients is therefore required.

\section{Global Risk}

The SYNTAX trial established a complex interaction between the EuroSCORE and the SXscore. The need to combine the angiographic and clinical scores into a single approach consequently became evident [45].

The Global Risk approach (Table 2) aims to potentially combine established historically accepted clinical variables from the EuroSCORE $[5,6]$ with anatomical variables from the SXscore [7, 9, 14] to allow for a Global Risk assessment for patients proposing to undergo revascularization with PCI [45]. By adopting this approach, the same risk model could potentially be used by the Heart Team to appropriately risk stratify patients proposing to undergo $\mathrm{PCI}$ or CABG. This may potentially increase the number of patients who could safely and efficaciously be treated with PCI compared to the use of the SYNTAX score alone.

In variants of this model, one group has previously demonstrated the potential of the Global Risk model to enhance risk stratification among patients who underwent LMS PCI from a single-center registry $[43,46]$. A major criticism of their approach has been the lack of consistency in their application of the Global Risk model. The range of scores within each tertile of risk for the EuroSCORE and SXscores has been established as described earlier [5-7, 9, 14]. Yet in the two publications using the Global Risk approach by the same group $[43,46]$, a different range of scores for the tertiles of risk for the EuroSCORE and SXscores has been used [46, 47]. It is the authors' opinions that the established range of scores for the tertiles of risk for the EuroSCORE and SXscore (Fig. 1) should be maintained to allow the application of the Global Risk model across surgical and PCI populations, and importantly allow for a consistency in the ranges of scores that will make application of the model by other groups possible and ultimately may allow validation of this risk model in the future, should this risk model prove feasible. Further study into the concept of a Global Risk approach utilizing the EuroSCORE and SXscores with ranges of risks based on consistently defined values for the EuroSCORE and SXscore tertiles are forthcoming.

\section{Risk/Benefit Analysis}

Undoubtedly, both PCI and CABG allow for an improvement in the quality of life for patients. However, one of the main drawbacks of using contemporary risk models for both PCI and $C A B G$ is that the role of the individual patient, their personal preferences, and perception of risk may be underestimated. To address this issue, the novel concept of a clinical model that balances the risks and benefits of the proposed revascularization procedure has recently emerged [48•].

Table 2 The concept of the Global Risk approach, combining the additive EuroSCORE and SYNTAX score (SXscore) using historically defined tertiles of risk for the EuroSCORE $[5,26]$ and the SYNTAX trial-defined ranges for SXscore [1,7]

\begin{tabular}{llll}
\hline & $\begin{array}{l}\text { Low SXscore } \\
(\leq 22)\end{array}$ & $\begin{array}{l}\text { Intermediate } \\
\text { SXscore } \\
(23-32)\end{array}$ & $\begin{array}{l}\text { High SXscore } \\
(\geq 33)\end{array}$ \\
\hline $\begin{array}{l}\text { Low additive } \\
\text { EuroSCORE } \\
(0-2)\end{array}$ & Low risk & Low risk & $\begin{array}{c}\text { Intermediate } \\
\text { risk }\end{array}$ \\
$\begin{array}{l}\text { Intermediate additive } \\
\text { EuroSCORE } \\
(3-5)\end{array}$ & Low risk & Low risk & $\begin{array}{c}\text { Intermediate } \\
\text { risk }\end{array}$ \\
$\begin{array}{l}\text { High additive } \\
\text { EuroSCORE } \\
(\geq 6)\end{array}$ & $\begin{array}{c}\text { Intermediate } \\
\text { risk }\end{array}$ & $\begin{array}{c}\text { Intermediate } \\
\text { risk }\end{array}$ & High risk \\
\hline
\end{tabular}

EuroSCORE European system for cardiac operative risk evaluation, SYNTAX synergy between percutaneous coronary intervention with taxus and cardiac surgery 
Essentially the need for some individuals to remain active within their professional/personal lives may be vital, and they would thus potentially be more prepared to accept the longerterm risks associated with $\mathrm{PCI}$ - namely increased revascularization - to remain at their present functional state, in exchange for being free from the short-term morbidity associated with $\mathrm{CABG}$. The latter being predominantly related to the intrinsically more invasive nature of the $\mathrm{CABG}$ procedure (eg, thoracotomy and vein harvesting and subsequent sternotomy and leg pain) [49, 50]. However, individual patients may value this risk/benefit tradeoff differently. For some, exchanging the increased risk of repeat PCI or CABG to obtain short-term pain relief and a rapid return to full mobility will be acceptable, whereas others may prefer to endure short-term pain to obtain a higher probability of avoiding a subsequent revascularization. Patients may also prefer to risk undergoing multiple PCI procedures rather than a single $\mathrm{CABG}$, or they may prefer to avoid the risk of requiring $\mathrm{CABG}$ subsequent to $\mathrm{PCI}$ and instead have $\mathrm{CABG}$ initially. Consequently, from the patient's perspective, the balance between these conflicting considerations appears to play a crucial role in the identification of the preferred revascularization strategy.

Federspiel et al. [48•] recently applied this concept to the ARTS I population, by quantifying the tradeoff between the risks and benefits of PCI versus CABG for patients with multivessel disease [42]. Although this study was performed on study data that were over 10 years old, in a population who had implantation of bare-metal stents, the results were nevertheless supportive of this concept and allowed for the first time a quantification of a level of risk that a patient would be willing to accept to maintain their present functional state. Data from the SYNTAX and other trials on this very concept to reflect more contemporary practice with drug-eluting stents are forthcoming.

\section{Conclusions}

It would appear that a combination of clinical and anatomical variables are required for an effective, clinically useful risk model for patients with complex coronary artery disease proposing to undergo multivessel PCI. Ideally this model would be simple to calculate and could be rapidly performed at the bedside. However, the need to include detailed anatomical assessments appears evident, such as the incorporation of the SXscore. The pragmatic approach appears in developing and refining a risk model that incorporates both elements in as simple a way as possible. Concepts such as the noninvasive calculation of the Functional SYNTAX score may serve to streamline this process and the concept of patient-empowered risk/benefit tradeoff are potential further areas for research.
Acknowledgments V. Farooq wishes to thank the Dickinson Trust Travelling Scholarship, Manchester Royal Infirmary, Manchester, England, United Kingdom.

Disclosure No potential conflicts of interest relevant to this article were reported.

Open Access This article is distributed under the terms of the Creative Commons Attribution Noncommercial License which permits any noncommercial use, distribution, and reproduction in any medium, provided the original author(s) and source are credited.

\section{References}

Papers of particular interest, published recently, have been highlighted as:

- Of importance

1. Serruys PW, Morice MC, Kappetein AP, Colombo A, Holmes DR, Mack MJ, et al. Percutaneous coronary intervention versus coronary-artery bypass grafting for severe coronary artery disease. N Engl J Med. 2009;360(10):961-72.

2. Kappetein AP, Feldman TE, Mack MJ, Morice M, Holmes DR, Ståhle E, et al. Comparison of Coronary Bypass Surgery with Drug-eluting Stenting for the Treatment of Left Main and/or Three-vessel Disease: Three-year follow-up of the SYNTAX trial. In Press 2011. This paper discusses the 3-year follow-up data of the landmark SYNTAX trial comparing CABG against PCI demonstrating different outcomes within the LMS and $3 V D$ cohorts.

3. Ong AT, Serruys PW, Mohr FW, Morice MC, Kappetein AP, Holmes Jr DR, et al. The SYNergy between percutaneous coronary intervention with TAXus and cardiac surgery (SYNTAX) study: design, rationale, and run-in phase. Am Hear J. 2006;151 (6):1194-204.

4. Kolh P, Wijns W, Danchin N, Di Mario C, Falk V, Folliguet T, et al. Guidelines on myocardial revascularization. Eur J Cardiothorac Surg. 38 Suppl:S1-S52.

5. Nashef SA, Roques F, Michel P, Gauducheau E, Lemeshow S, Salamon R. European system for cardiac operative risk evaluation (EuroSCORE). Euro J Cardiothorac Surg: official journal of the European Association for Cardio-thoracic Surgery. 1999;16(1):9-13.

6. Roques F, Michel P, Goldstone AR, Nashef SA. The logistic EuroSCORE. Eur Hear J. 2003;24(9):881-2.

7. Serruys PW, Onuma Y, Garg S, Sarno G, van den Brand M, Kappetein AP, et al. Assessment of the SYNTAX score in the Syntax study. EuroIntervention. 5(1):50-56.

8. Leaman DM, Brower RW, Meester GT, Serruys P, van den Brand M. Coronary artery atherosclerosis: severity of the disease, severity of angina pectoris and compromised left ventricular function. Circulation. 1981;63(2):285-99.

9. Sianos G, Morel MA APK, Morice MC, Colombo A, Dawkins K, van den Brand M, et al. The SYNTAX Score: an angiographic tool grading the complexity of coronary artery disease. EuroIntervention. 2005;1:219-27.

10. Coronary Stenosis Imaging, Structure and Physiology. Javier Escaned. Patrick W Serruys. PCR Publishing; 2011.

11. Khattab AA, Hamm CW, Senges J, Toelg R, Geist V, Bonzel T, et al. Prognostic value of the modified American College of Cardiology/American Heart Association lesion morphology classification for clinical outcome after sirolimus-eluting stent 
placement (results of the prospective multicenter German Cypher Registry). Am J Cardiol. 2008;101(4):477-82.

12. Valgimigli M, Dawkins K, Macaya C, de Bruyne B, Teiger E, Fajadet $\mathrm{J}$, et al. Impact of stable versus unstable coronary artery disease on 1-year outcome in elective patients undergoing multivessel revascularization with sirolimus-eluting stents: a subanalysis of the ARTS II trial. J Am Coll Cardiol. 2007;49(4):431-41.

13. Capodanno D, Di Salvo ME, Cincotta G, Miano M, Tamburino C. Usefulness of the SYNTAX score for predicting clinical outcome after percutaneous coronary intervention of unprotected left main coronary artery disease. Circ Cardiovasc Interv. 2009;2(4):302-8.

14. SYNTAX score calculator: http://www.syntaxscore.com. SYNTAX working-group. Launched 19th May 2009.

15. Garg S, Stone GW, Kappetein AP, Sabik JF, Simonton C, Serruys PW. Clinical and angiographic risk assessment in patients with left main stem lesions. JACC Cardiovasc Interv. 2010;3(9):891-901.

16. Wykrzykowska JJ, Garg S, Girasis C, de Vries T, Morel MA, van Es GA, et al. Value of the SYNTAX score for risk assessment in the all-comers population of the randomized multicenter LEADERS (Limus Eluted from A Durable versus ERodable Stent coating) trial. J Am Coll Cardiol. 2010;56(4):272-7.

17. Mohr FW, Rastan AJ, Serruys PW, Kappetein AP, Holmes DR, Pomar JL, et al. Complex coronary anatomy in coronary artery bypass graft surgery: impact of complex coronary anatomy in modern bypass surgery? Lessons learned from the SYNTAX trial after two years. J Thorac Cardiovasc Surg. 2011;141(1):130-40.

18. Tonino PA, Fearon WF, De Bruyne B, Oldroyd KG, Leesar MA, Ver Lee PN, et al. Angiographic versus functional severity of coronary artery stenoses in the FAME study fractional flow reserve versus angiography in multivessel evaluation. J Am Coll Cardiol. 2010;55(25):2816-21.

19. Pijls NH, Fearon WF, Tonino PA, Siebert U, Ikeno F, Bornschein $\mathrm{B}$, et al. Fractional flow reserve versus angiography for guiding percutaneous coronary intervention in patients with multivessel coronary artery disease: 2-year follow-up of the FAME (Fractional Flow Reserve Versus Angiography for Multivessel Evaluation) study. J Am Coll Cardiol. 2010;56(3):177-84.

20. Tonino PA, De Bruyne B, Pijls NH, Siebert U, Ikeno F, van' t Veer $\mathrm{M}$, et al. Fractional flow reserve versus angiography for guiding percutaneous coronary intervention. N Engl J Med. 2009;360 (3):213-24.

21. Fearon WF. Functional Syntax score. Presented at: Left Main Coronary Interventions Course; February 14, 2011; New York, NY.

22. Cutlip DE, Mehran R, Vranckx P. FAME and coronary stent investigations: is there a kink in the wire? J Am Coll Cardiol. 2011;57(1):115-6. author reply 116 .

23. Garg S, Girasis C, Sarno G, Goedhart D, Morel MA, GarciaGarcia HM, et al. The SYNTAX score revisited: a reassessment of the SYNTAX score reproducibility. Catheter Cardio Interv. 75 (6):946-952

24. Singh M, Rihal CS, Lennon RJ, Spertus J, Rumsfeld JS, Holmes $\mathrm{Jr}$ DR. Bedside estimation of risk from percutaneous coronary intervention: the new Mayo Clinic risk scores. Mayo Clin Proc. 2007;82(6):701-8.

25. Singh M, Gersh BJ, Li S, Rumsfeld JS, Spertus JA, O'Brien SM, et al. Mayo Clinic Risk Score for percutaneous coronary intervention predicts in-hospital mortality in patients undergoing coronary artery bypass graft surgery. Circulation. 2008;117(3):356-62.

26. Gogbashian A, Sedrakyan A, Treasure T. EuroSCORE: a systematic review of international performance. Eur J Cardiothorac Surg. 25(5):695-700

27. Kim YH, Ahn JM, Park DW, Lee BK, Lee CW, Hong MK, et al. EuroSCORE as a predictor of death and myocardial infarction after unprotected left main coronary stenting. Am J Cardiol. 2006;98(12):1567-70.
28. Romagnoli E, Burzotta F, Trani C, Siviglia M, Biondi-Zoccai GG, Niccoli G, et al. EuroSCORE as predictor of in-hospital mortality after percutaneous coronary intervention. Heart. 2009;95(1):43-8.

29. • Kim Y-H, Park D-W, Kim W-J, Lee J-Y, Yun S-C, Kang S-J, et al. Validation of SYNTAX (Synergy between PCI with Taxus and Cardiac Surgery) score for prediction of outcomes after unprotected left main coronary revascularization. J Am Coll Cardiol Intv. 2010;3 (6):612-23. This paper discusses the concept of the EuroSCORE being a predictor of outcomes in unprotected left main stenting.

30. Morice MC, Serruys PW, Kappetein AP, Feldman TE, Stahle E, Colombo A, et al. Outcomes in patients with de novo left main disease treated with either percutaneous coronary intervention using paclitaxel-eluting stents or coronary artery bypass graft treatment in the Synergy Between Percutaneous Coronary Intervention with TAXUS and Cardiac Surgery (SYNTAX) trial. Circulation. 2010;121(24):2645-53.

31. Rodes-Cabau J, Deblois J, Bertrand OF, Mohammadi S, Courtis J, Larose E, et al. Nonrandomized comparison of coronary artery bypass surgery and percutaneous coronary intervention for the treatment of unprotected left main coronary artery disease in octogenarians. Circulation. 2008;118(23):2374-81.

32. Onuma Y, Girasis C, Piazza N, Garcia-Garcia HM, Kukreja N, Garg S, et al. Long-term clinical results following stenting of the left main stem: insights from RESEARCH (Rapamycin-Eluting Stent Evaluated at Rotterdam Cardiology Hospital) and TSEARCH (Taxus-Stent Evaluated at Rotterdam Cardiology Hospital) Registries. JACC Cardiovasc Interv. 2010;3(6):584-94.

33. Ranucci M, Castelvecchio S, Menicanti L, Frigiola A, Pelissero G. Risk of assessing mortality risk in elective cardiac operations: age, creatinine, ejection fraction, and the law of parsimony. Circulation. 2009;119(24):3053-61.

34. - Ranucci M, Castelvecchio S. The ACEF score one year after: a skeleton waiting for muscles, skin, and internal organs. EuroIntervention. 6(5):549-553. This is an excellent editorial summarizing the application of the ACEF score in cardiothoracic patients and attempts at its application within PCI patients in combination with anatomical-based risk scores.

35. Wykrzykowska JJ, Garg S, Onuma Y, de Vries T, Goedhart D, Morel MA, et al. Value of age, creatinine, and ejection fraction (ACEF score) in assessing risk in patients undergoing percutaneous coronary interventions in the 'All-Comers' LEADERS trial. Circ Cardiovasc Interv. 2011;4(1):47-56.

36. Parsonnet V, Dean D, Bernstein AD. A method of uniform stratification of risk for evaluating the results of surgery in acquired adult heart disease. Circulation. 1989;79(6 Pt 2):I3-12.

37. Valgimigli $\mathrm{M}$, van Mieghem CAG, Ong ATL, Aoki J, Granillo GAR, McFadden EP, et al. Short- and long-term clinical outcome after drug-eluting stent implantation for the percutaneous treatment of left main coronary artery disease: insights from the rapamycin-eluting and taxus stent evaluated at rotterdam cardiology hospital registries (RESEARCH and T-SEARCH). Circulation. 2005;111(11):1383-9.

38. Chakravarty T, Buch MH, Naik H, White AJ, Doctor N, Schapira J, et al. Predictive accuracy of SYNTAX score for predicting longterm outcomes of unprotected left main coronary artery revascularization. Am J Cardiol. 2011;107(3):360-6.

39. Walter J, Mortasawi A, Arnrich B, Albert A, Frerichs I, Rosendahl $\mathrm{U}$, et al. Creatinine clearance versus serum creatinine as a risk factor in cardiac surgery. BMC Surg. 2003;3:4.

40. Cockcroft DW, Gault MH. Prediction of creatinine clearance from serum creatinine. Nephron. 1976;16(1):31-41.

41. Garg S, Sarno G, Garcia-Garcia HM, Girasis C, Wykrzykowska J, Dawkins KD, et al. A new tool for the risk stratification of patients with complex coronary artery disease: the Clinical SYNTAX Score. Circ Cardiovasc Interv. 2010;3(4):317-26. 
42. Serruys PW, Ong AT, Morice MC, De Bruyne B, Colombo A, Macaya C, et al. Arterial Revascularisation Therapies Study Part II - Sirolimus-eluting stents for the treatment of patients with multivessel de novo coronary artery lesions. EuroIntervention. 1(2):147-156

43. Capodanno D, Caggegi A, Miano M, Cincotta G, Dipasqua F, Giacchi G, et al. Global risk classification and clinical SYNTAX (Synergy between percutaneous coronary intervention with TAXUS and cardiac surgery) score in patients undergoing percutaneous or surgical left main revascularization. J Am Coll Cardiol Intv. 2011;4(3):287-97.

44. Chen S-L, Chen JP, Mintz G, Xu B, Kan J, Ye F, et al. Comparison between the NERS (New Risk Stratification) score and the SYNTAX (Synergy Between Percutaneous Coronary Intervention With Taxus and Cardiac Surgery) score in outcome prediction for unprotected left main stenting. J Am Coll Cardiol Intv. 2010;3 (6):632-41.

45. Serruys PW. Integrating lessons from recent clinical trials into practice: beyond the SYNTAX score. Presented at: Transcatheter Therapeutics Asia Pacific; April 29, 2010; Seoul, South Korea; 2010.

46. Capodanno D, Miano M, Cincotta G, Caggegi A, Ruperto C, Bucalo R, et al. EuroSCORE refines the predictive ability of SYNTAX score in patients undergoing left main percutaneous coronary intervention. Am Hear J. 2010;159(1):103-9.

47. Capodanno D, Capranzano P, Di Salvo ME, Caggegi A, Tomasello $D$, Cincotta $G$, et al. Usefulness of SYNTAX score to select patients with left main coronary artery disease to be treated with coronary artery bypass graft. JACC Cardiovasc Interv. 2009;2 (8):731-8.

48. - Federspiel J, Stearns SC, van Domburg R, Sheridan BC, Lund J, Serruys PW. Risk-benefit trade-offs in revascularisation choices. EuroInternvention 2011, Epub ahead of print. This paper discusses the innovative concept of risk/benefit tradeoff in the choice of coronary revascularization modality.

49. van Domburg RT, Daemen J, Morice MC, de Bruyne B, Colombo A, Macaya C, et al. Short- and long-term health related quality-oflife and anginal status of the Arterial Revascularisation Therapies Study part II, ARTS-II; sirolimus-eluting stents for the treatment of patients with multivessel coronary artery disease. EuroIntervention. 5(8):962-967.
50. Cohen DJ, Van Hout B, Serruys PW, Mohr FW, Macaya C, den Heijer P, et al. Quality of life after PCI with drug-eluting stents or coronary-artery bypass surgery. N Engl J Med. 364(11):10161026.

51. Graham MM, Faris PD, Ghali WA, Galbraith PD, Norris CM, Badry JT, et al. Validation of three myocardial jeopardy scores in a population-based cardiac catheterization cohort. Am Hear J. 2001;142(2):254-61.

52. - Peterson ED, Dai D, DeLong ER, Brennan JM, Singh M, Rao $\mathrm{SV}$, et al. Contemporary mortality risk prediction for percutaneous coronary intervention: results from 588,398 procedures in the National Cardiovascular Data Registry. J Am Coll Cardiol. 2010;55(18):1923-32. This paper discusses a contemporary model for predicting mortality risk after PCI.

53. O'Connor GT, Plume SK, Olmstead EM, Coffin LH, Morton JR, Maloney CT, et al. Multivariate prediction of in-hospital mortality associated with coronary artery bypass graft surgery. Northern New England Cardiovascular Disease Study Group. Circulation. 1992;85(6):2110-8.

54. Hannan EL, Wu C, Bennett EV, Carlson RE, Culliford AT, Gold JP, et al. Risk stratification of in-hospital mortality for coronary artery bypass graft surgery. J Am Coll Cardiol. 2006;47(3):661-8.

55. Shroyer AL, Coombs LP, Peterson ED, Eiken MC, DeLong ER, Chen A, et al. The Society of Thoracic Surgeons: 30-day operative mortality and morbidity risk models. Ann Thorac Surg. 2003;75 (6):1856-64. discussion 1864-1855.

56. Shahian DM, O'Brien SM, Filardo G, Ferraris VA, Haan CK, Rich JB, et al. The Society of Thoracic Surgeons 2008 cardiac surgery risk models: part 1-coronary artery bypass grafting surgery. Ann Thorac Surg. 2009;88(1 Suppl):S2-22.

57. Ad N, Barnett SD, Speir AM. The performance of the EuroSCORE and the Society of Thoracic Surgeons mortality risk score: the gender factor. Interact Cardiovasc Thorac Surg. 2007;6 (2):192-5.

58. Madan P, Elayda MA, Lee VV, Wilson JM. Predicting major adverse cardiac events after percutaneous coronary intervention: $t$. Am Hear J. 2008;155(6):1068-74.

59. Wu C, Hannan EL, Walford G, Ambrose JA, Holmes Jr DR, King 3rd SB, et al. A risk score to predict in-hospital mortality for percutaneous coronary interventions. J Am Coll Cardiol. 2006;47 (3):654-60. 